\title{
Comparison of Lightweight and Solid Milling Cutter Capabilities
}

Pavel Hanzl, Ivana Zetková, Miroslav Zetek

Faculty of Mechanical Engineering, University of West Bohemia. Univerzitní 2732/8, 30614 Pilsen. Czech Republic.E-mail: hanzlp@rti.zcu.cz, zetkova@rti.zcu.cz,mzetek@rti.zcu.cz

\begin{abstract}
Milling is one of the oldest methods of metal machining. This technology has been developed over a long time. The last milestone is the use of composite materials for the construction of cutting tools. However, there are other possibilities for improvement offered by new production methods such as Metal Additive Manufacturing. The paper deals with machining experiments using a lightweight milling cutter with a lattice structure. The results of machining are compared to the capabilities of a solid milling cutter. The evaluated parameters are: cutting forces and wear on cutting edge. Based on these parameters, it was not possible to confirm the benefit of the lightweight version for machining.
\end{abstract}

Keywords: Milling Tool, Topological Optimization, Direct Melting Laser Sintering, Metal Additive Manufacturing

\section{Introduction}

Longer tool life can be achieved by a higher feed rate using a high speed spindle. This mechanism of tool life improvement has not been clarified completely yet. [1] The higher dynamic of a solid milling tool requires a powerful spindle drive and means the machine-tool-workpiece system is more stressed. In this regard, a lightweight cutter reduces inertial load and the cutting forces may be balanced due to its lower stiffness. The consequence is improved tool life because the force effects are more evenly distributed between the cutting edges of cutter. [1]

The lightweight cutter is produced by Direct Metal Laser Sintering (DMLS) technology. This technology is based on the powder bed principle of Additive Manufacturing (AM). This technology has been the subject of many publications. Generally, a printed part must be subsequently machined by conventional technology such as turning or milling operations because the printed surface is rough [2]. Kellner [3] deals with production systems using AM and conventional machining technologies. This production system is flexible, but has difference demands, mainly due to the long AM production times. Result of the study was that the technology can be used for serial production.

The design of a milling cutter must respect the possibilities of the production technology used. A modified lattice core is based on BCC topology. According to Syam et al. [6], the strut-based lattice design has the potential to enhance the mechanical vibration insulation properties. A solid structure does not insulate vibration, but rather, the structure attenuates the vibration amplitude. [8] However, this statement has not yet been successfully confirmed by experimental testing of lightweight cutter.
Lightweight and energy-absorbing materials are interesting for a variety of industries, and the machining industry is no exception. The concept of a lightweight cutter has the potential to be successful in terms of endurance against cutting forces and increasing its natural frequencies. The shell of the cutter includes a lattice core which is designed to be self-supporting, which guarantees manufacturability without support structures.

The experiments, done under laboratory milling conditions with single cutting tooth, allowed the validation of the proposed lightweight cutter design and will serve to further improve its properties in comparison with the solid version. The optimum for operation of lightweight cutter may occur at specific spindle speed ranges, which takes a lot of time. The cutter design needs to be continually tuned to achieve real improvements.

The stiffness will be adapted based on the surface regeneration effect between adjacent cutting teeth. Lower stiffness can cause destabilization of the regenerative effect as well as variable pitch [7]. However, finding the correct settings will be difficult and this paper presents the first steps.

\section{Design and manufacturing of the cutter}

The core of the cutter is composed of a modified lattice structure. The basis is BCC topology, which changes the angle between the struts. This solution ensures the continual connection of struts between clusters. The volume fraction was set at $18.7 \%$ and strut diameter is $1.19 \mathrm{~mm}$. Lattice structures in this cutter have a constant strut diameter. The struts grow at $38^{\circ}$, which is sufficient for the reliable production of BCC topology. The shell of the cutter body has a thickness of $2.3 \mathrm{~mm}$ and a diameter of $125 \mathrm{~mm}$. The issue of 
geometry and stress-strain analyses is described in more detail in a separate paper [4].

The design of the lightweight cutter was produced by an EOS M290 printer from maraging steel 1.2709 according to European classification. Additional machining of the functional surfaces was done on a multifunctional turning centre DMG CTX BETA 1250. The workpiece of lightweight cutter is shown in Figure 1. In order to compare the results, a solid version of the cutter was also manufactured.

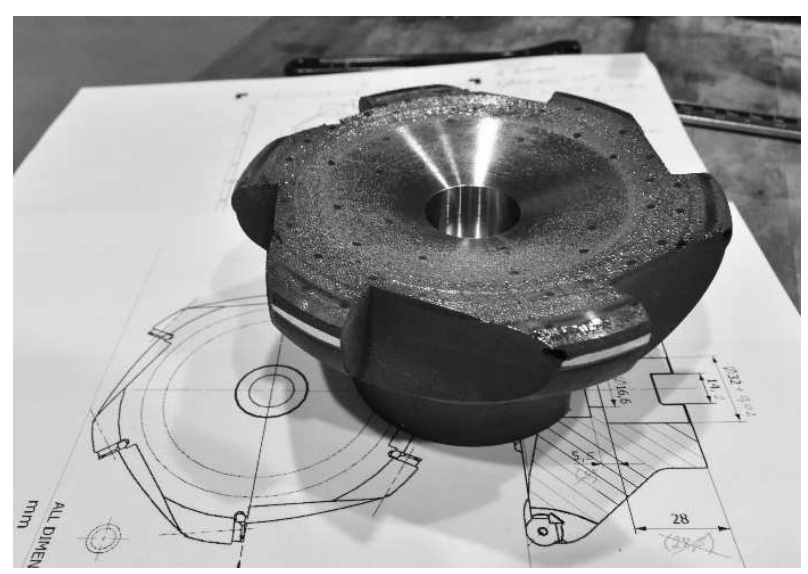

Fig. 1 Printed workpiece of lightweight cutter for machining

\section{Methods and experiment}

Experimental machining of superalloy Inconel 718 was chosen for verification. Two parameters were measured and cutting forces, wear of the cutting edge of the circular insert. Cutting conditions were: cutting speed $20 \mathrm{~m} / \mathrm{min}$, feed $0.18 \mathrm{~mm}$ per insert, depth of cut $0.5 \mathrm{~mm}$ and width of cutting zone $37.5 \mathrm{~mm}(30 \%$ of diameter).

DMG MORI DMU 40 eVo linear milling centre was used for experimental testing. KISTLER type 9255 dynamometer was used to measure force components during machining. Tool wear measurement points are every four minutes (after each $36 \mathrm{~mm}$ ). Due to the strengthening of thin layers of Inconel 718, down milling (climb milling) was selected for machining this material. The milling cutters had one circular insert during the experiments. The used type of insert was PHOENIX RPTH1204M8EN-SM from OSG Corporation. The assembly is shown in Figure 2.

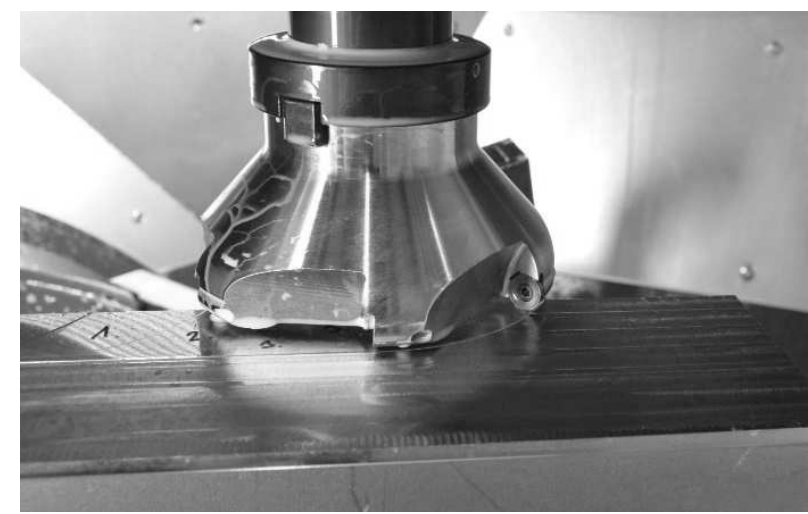

Fig. 2 Assembly for testing; the lightweight cutter with one circular insert and workpiece of Inconel 718

Before the machining experiments, the natural frequency was measured using equipment from Brüel \& Kjaer to measure the oscillation: an accelerometer 4524B, impact hammer 8206-003, and electronic module 3160-A-042. The frequency range of this measuring assembly is $0.2 \mathrm{~Hz}$ to $12.8 \mathrm{kHz}$ and resonance frequency of the accelerometer was $18 \mathrm{kHz}$ which is more than sufficient for the experiment. The cutter assembly was clamped in the spindle of the milling machine. The accelerometer was fixed on the surface of the insert bed. The measured dynamic responses are shown in Figure 3. The first resonance frequencies should correspond to cutting speeds of 7050 $\mathrm{m} / \mathrm{min}$ for the lightweight cutter and $5660 \mathrm{~m} / \mathrm{min}$ for the solid version. Obviously, these cutting speeds are high in both cases and the cutters will never be exposed to this dynamics.

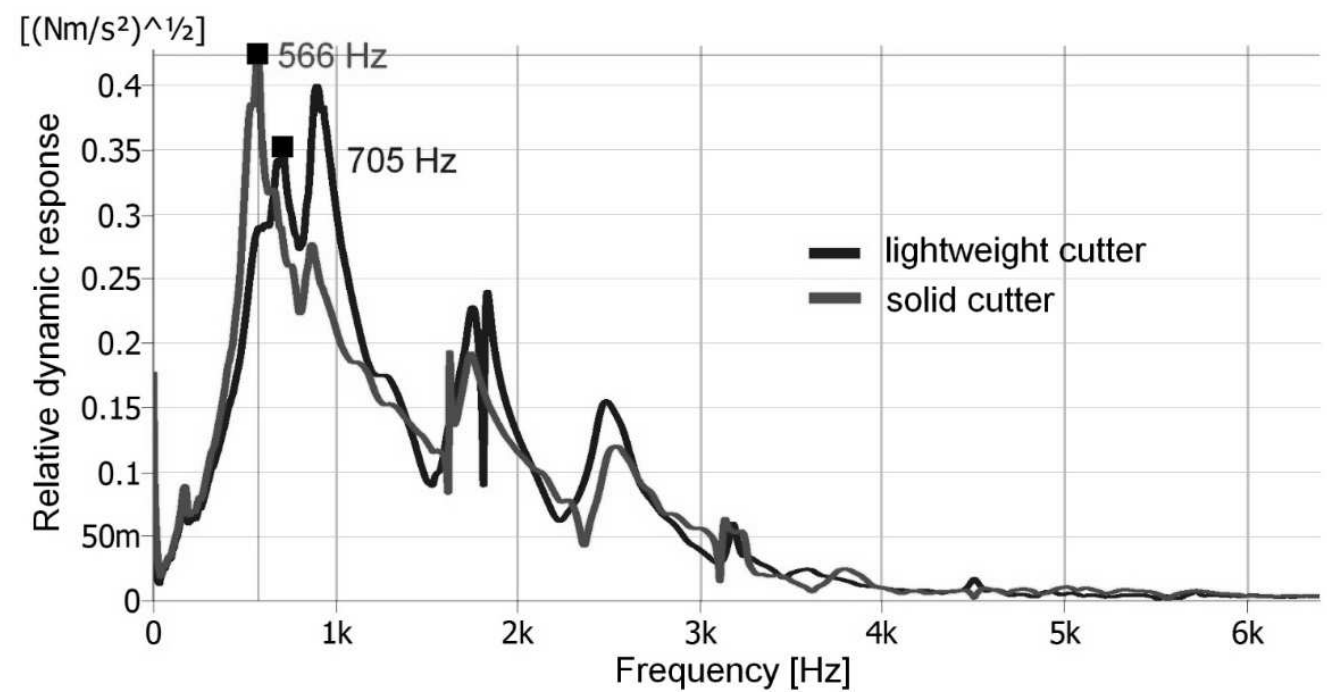

Fig. 3 Dynamic responses of cutters in the spindle of milling centre 
The surface roughness was measured using the workshop tester Mahr MarSurf M 300. The cutting edge wear was monitored by a Blickle Multicheck PC500 microscope for each path of the cutter after 36 $\mathrm{mm}$ (4 minutes).

The measured values of force components $F x, F y$ and $F_{z}$ are shown in Figure 4. Slightly higher cutting

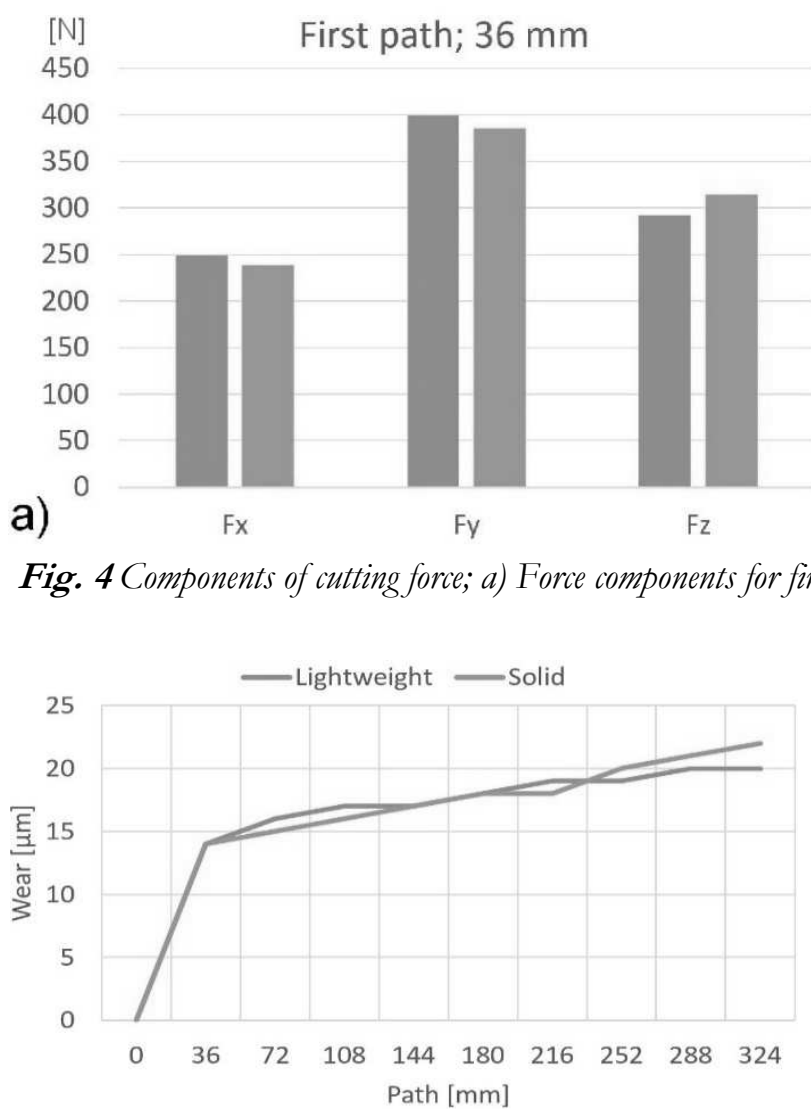

Fig. 5 Flank wear $V B_{B}$ according ISO 3685 standard

\section{Results and discussion}

According to the cutting conditions, each insert is in the cut for 0.221 second. This is calculated based on mathematical formula 1.

$$
\omega=\frac{v}{r}=\frac{\varphi}{t} ;[\operatorname{rad} / s]
$$

$\omega \ldots . .$. angular velocity

$v$..... linear velocity

r.......radius of cutter

ф.......angular displacement; tool engagement angle (TEA)

The analysis of the Fx force component signal detects anomalies outside of TEA, see detail in Figure 6. Similar behaviour was observed in other force components Fy and Fz. This may be a consequence of the lower stiffness of the lightweight cutter and the measured force is a record of the relaxation of the elastic deformation of the lightweight cutter outside the cutting area. The anomalies reach maximum values of forces are evident in the lightweight version. The surface roughness parameters are comparable between the cutters. The arithmetical surface roughness reached values in the range $\mathrm{Ra} 0.22 \mu \mathrm{m}-\mathrm{Ra} 0.31 \mu \mathrm{m}$. The level of cutting edge wear is shown in Figure 5, and there is no obvious difference between the cutters.

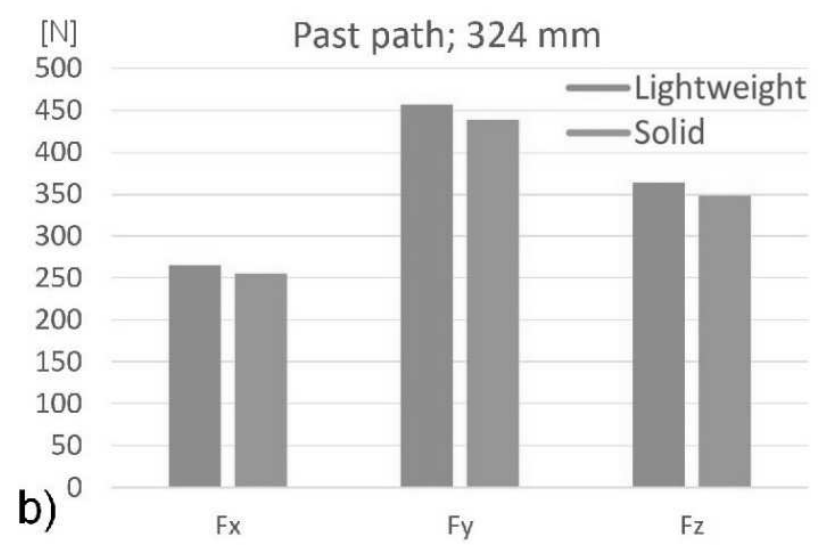


with regard to the chosen machined material, which is very difficult to machine. The cutter geometry and insert selection has been adapted to this.

The results show similar behaviour during milling with one circular insert. However, an anomaly was observed in the record of force components during machining of Inconel 718. Some other oscillations were recorded shortly after the insert left the cutting area. This phenomenon is the consequence of the lower rigidity of the lightweight cutter. This is in correlation with the results of FEA in the work of Hanzl et al. [4] where displacement of the insert centre in the radial direction of the cutter was many times higher for the lightweight cutter than the solid version.

As evidenced from results of Takashi Miyaguchi et al. [1], the tool life can be prolonged by reducing tool stiffness. This was confirmed from various tool stiffness related to the tool length on small ball end mills. Lower stiffness does not affect the other monitored parameters, surface quality or cutting edge wear. The only difference was found in the force load of the insert, where the force components were higher about $5 \%$ than the solid cutter.

This increase cannot be caused by various cutting depths of the inserts or the cutter diameter, because the correct settings of the cutting tools were verified by the measuring machine Zoller Genius 3. With this in mind, the slight increase of the load force must be a manifestation of the different stiffness and oscillations (see Fig.5).

Reduced rigidity can have a positive effect on tool life when a high velocity of the milling spindle is used for increasing the feed rate because the cutting forces are better balanced. [1] This could not be experimentally verified on the lightweight cutter with the full number inserts due to inaccuracies in the final machining of the cutters. Further steps will be to integrate cooling channels into a new design and refine the finishing machining of the insert beds for experimental tests.

The accuracy of machining of the insert beds directly influences all parameters measured during the experiments, whereas the integration of cooling channels mainly improves the tool life, as in the work of Popov [5].

\section{Acknowledgement}

This paper was supported by the Internal Grant Agency of the University of West Bohemia, project No. SGS-2019-008.

\section{References}

[1] MIYAGUCHI, T., MASUDA, M., TAKEOKA, E., IWABE, H. (2001) Effect of tool stiffness upon tool wear in high spindle speed milling using small ball end mill, Precision Engineering, ISSN 0141-6359, Vol. 25, Issue 2, 2001, Pp. 145-154

[2] DVORAK, K., ZARYBNICKA, L., DVORAKOVA, J. (2019) Quality Parameters of 3D Print Products by the DMLS Method, Published by Manufacturing Technology, ISSN 1213-2489, April 2019, Vol. 19, No. 2, Pp. 209215

[3] KELLNER, T., KYNCL, J., PITRMUC, Z., BERANEK, L., KANAK, M., KYNCL, M. (2019) Production Process Planning in Additive Manufacturing and Conventional Machining Technology Manufacturing System, $\mathrm{Pu}-$ blished by Manufacturing Tecbnology, ISSN 12132489, April 2019, Vol. 19, No. 2, Pp. 232-237

[4] HANZL, P., ZETEK, M., RULC, V., PURŠ, H., ZETKOVÁ, I. (2019) Finite Element Analysis of a Lightweight Milling Cutter for Metal Additive Manufacturing, Published by Manufacturing Technology, ISSN 1213-2489, October 2019, Vol. 19, No. 5, Pp. 753-758

[5] POPOV, A., KHRAMENKOV, M. (2019) Effect of Hydraulic Oil Entering the Cutting Fluid on the Tool Life and Roughness in Milling of Structural Steel, Published by Manufacturing Technology, ISSN 1213-2489, June 2019, Vol. 19, No. 3

[6] SYAM, W.P., JIANWEI, W., ZHAO, B., MASKERY, I., ELMADIH, W., LEACH, R. (2018) Design and analysis of strut-based lattice structures for vibration isolation, Published by Precision Engineering, ISSN 0141-6359, Vol. 52, Pp. 494-506.

[7] STEFAN, G., HAJDU, D., IGLESIAS, A., TAKACS, D., DOMBOVARI, Z. (2018) Ultimate capability of variable pitch milling cutters, CIRP Annals, ISSN 0007-8506, Vol. 67, Issue 1, 2018, Pp. 373-376

[8] SCHMITZ, T.L., SMITH, K.S. (2013) Mechanical vibrations. Modeling and measurement. DOI 10.1007/978-1-4614-0460-6 